\title{
CELEBRATING THE NINETIETH ANNIVERSARY OF THE CENTRAL AEROHYDRODYNAMIC INSTITUTE
}

\author{
S. L. Chernyshev \\ Central Aerohydrodynamic Institute (TsAGI), 1 Zhukovsky str., Zhukovsky, \\ 140180, Moscow Region, Russia, slc@tsagi.ru
}

Celebrating the ninetieth anniversary of the Central Aerohydrodynamic Institute on December 1, 2008, was a great day for domestic (Russian) science. The Central Aerohydrodynamic Institute (TsAGI) was founded 90 years ago by N. E. Zhukovsky, an outstanding scientist and professor at the Lomonosov Moscow State University and Bauman University in Moscow. A. N. Tupolev and members of the aerostatics study group supervised by Zhukovsky actively participated in the founding of the Institute.

TsAGI was intended to be a new class of institutes, where fundamental research would be strongly connected with concrete practical application in the field of national economy and, first of all, the development of aviation. Such an approach has proved to be the correct one, and now we can talk with confidence about TsAGI not only as an institute that played a primary role in the establishment of domestic aviation, but also as one of the world's greatest centers of the development of mechanics. The names of outstanding scientists related to TsAGI are N. E. Zhukovsky, S. A. Chaplygin, A. N. Tupolev, B. N. Yuryev, A. I. Nekrasov, M. A. Lavrentiev, M. D. Millionschikov, G. I. Petrov, L. N. Sretensky, V. V. Golubev, M. V. Keldysh, L. I. Sedov, N. E. Kotchin, S. A. Christyanovich, A. I. Makarevsky, L. S. Leibenzon, L. G. Loitsiansky, M. L. Mil, A. A. Dorodnitsyn, G. P. Svischev, V. V. Struminsky, G. S. Bushgens, A. F. Selikhov, V. V. Sychev, V. Y. Neiland, V. A. Yaroshevsky, and many others.

On January 14, 1919, just one and a half months after the foundation of the Institute, the TsAGI collegium decided to establish the periodical, TsAGI Transactions. The first issue of the periodical was published the same year as Zhukovsky's article On the Snowdrift and River Mud Accumulation. Since then, TsAGI Transactions and, later on, Air Forces Engineering and TsAGI Scientific Notes have been published, including the most significant and original results of the Institute's scientists' research.

N. E. Zhukovsky (Fig. 1) headed TsAGI until his death on March 17, 1921. After that, the Institute was directed by S. A. Chaplygin, an eminent mathematician and me- 


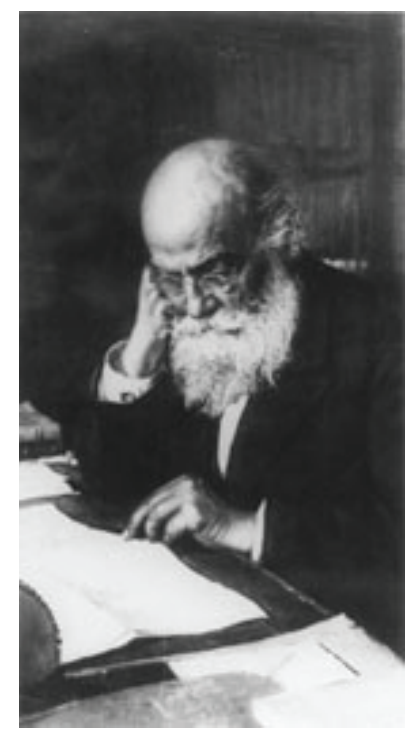

FIG. 1: Nikolay Egorovich Zhukovsky

chanical engineer, until 1931. During this period, the Moscow Experimental Centre (a branch of TsAGI today) was under intensive construction. This center involved aerodynamics, hydrodynamics, material and motor laboratories, and an airplane design office. The Institute was constantly growing; the number of its members increased from 41, in 1919 , to 400, in 1926. Chaplygin formed a powerful team of scientists who could effectively solve then-current theoretical and practical problems in mechanics. Development of airfoil theory, theory of airscrews, flutter theory, and theory of aircraft stability were significant contributions to aviation science. The first all-metal airplanes were built and the construction of the TsAGI helicopter was initiated under the direction of B. N. Yuryev. F. A. Tsander constructed and tested the first jet propulsion engine, OR-1.

The next stage of TsAGI development started in 1932, when the head of the Institute, N. M. Charlamov, made a request to the government for the establishing of a new center for full-scale experiments on aerodynamics and the solid aspects of airplane design. The center was built in less than five years on the site of today's town of Zhukovsky. The center included huge wind tunnels (Fig. 2) for full-scale experiments on airplanes (T101 and T104) and a solid-state department (Fig. 3).

The entire nation took part in building the center. The government at the highest level controlled the process of building and assisted in every way to finish with the building as soon as possible due to defense reasons. By the beginning of the Great Patriotic War (World War II), the major part of the experimental equipment was in operation.

Initially, the physical aviation units (airplanes, helicopters, balloons, etc.) were fully designed within the departments of TsAGI under the direction of outstanding aircraft designer A. N. Tupolev. A series of warplanes, passenger planes, transport planes, and 


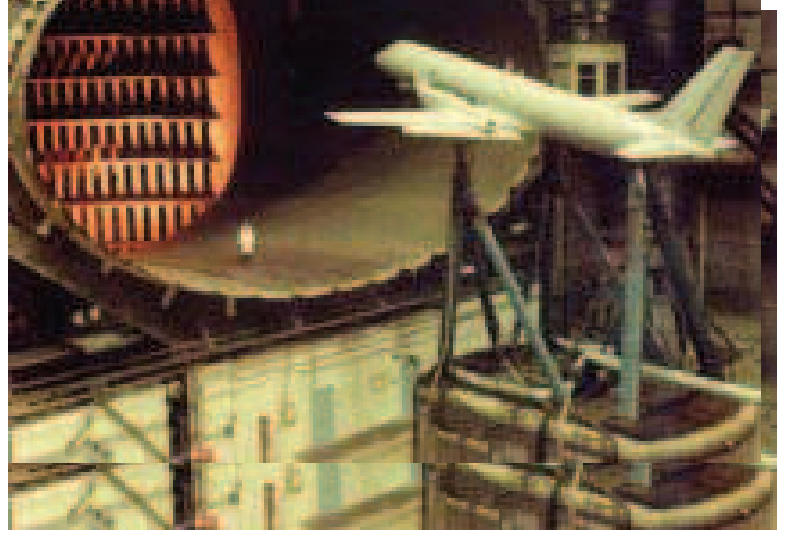

FIG. 2: T-101 wind tunnel

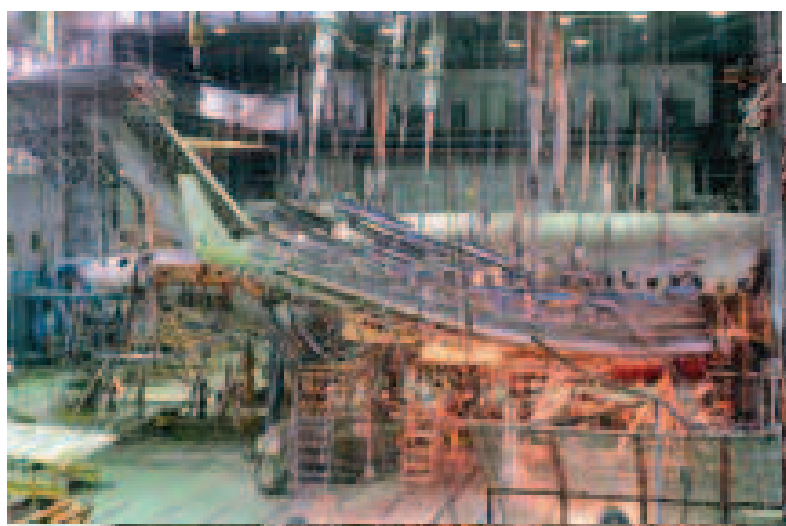

FIG. 3: The room of static strength in TsAGI

sporting planes (ANT1-ANT44) were designed. Due to the rapid development of aviation science, many independent institutes were formed on the basis of several TsAGI departments, which are active to the present day. They include the Institute of Airplane Engine Engineering, Hydroelectric Institute, Wind-Energetic Institute, Institute of Airplane Materials, and Scientific Flight-Research Institute. In 1936, the aircraft construction department was transformed into factory \#156, the famous Tupolev OKB (Tupolev Experimental Design Bureau).

During the same period, TsAGI took part in the construction of airships, helicopters, gyroplanes, motor sleighs, and motor torpedo boats. Vacuum fans designed by TsAGI were installed in the Moscow underground. The airplanes by TsAGI made it possible to hold new world records.

In 1936, V. P. Chkalov, G. F. Baidukov, and A. V. Beliayev flew an ANT-25 (Fig. 4) out of Moscow to Udd Island (Chkalov Island today). One year later, the same crew pi- 


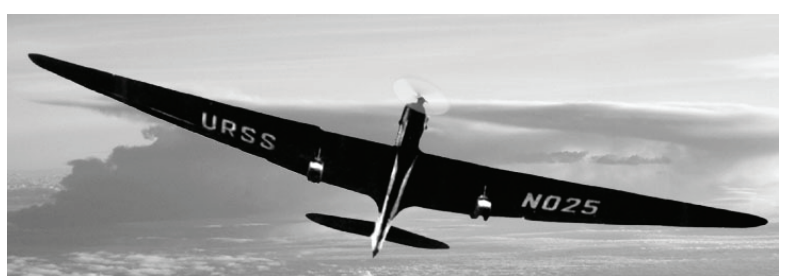

FIG. 4: ANT-25 aircraft

loted the same airplane from Moscow to Vancouver via the North Pole. A. B. Yumashev flew an ANT6 and set a record in carrying capacity and in reaching a maximum altitude with a given load. These are just a few special examples. It was a time of rapid development of aviation and aircraft science, and TsAGI accepted the challenge. The Institute was granted many awards by the government. In 1926, TsAGI received the Order of the Red Banner of Labor; in 1933, the Order of the Red Banner. Many employees received government awards. S. A. Chaplygin was the first Soviet scientist to receive the title of Hero of Socialist Labor in 1941.

During the Great Patriotic War, TsAGI scientists concentrated on the improvement of the characteristics of warplanes and arms, trying to achieve superiority of newly constructed airplanes over enemy aircraft. They also concentrated on the further development of aviation, which involved jet aviation. The Institute members were busy at these problems almost 24 hours a day. They managed to increase the full speed of flight and rate of climb, and improve engine behavior and the sturdiness of aircraft. Many significant results were obtained for the dependencies of airplane aerodynamics and stability on the compressibility of air. The first constructor's guides dedicated to reciprocating engine and propeller airplanes were published by TsAGI in 1943.

On July 5, 1941, the government (Council of the People's Commissars) decreed that certain TsAGI departments should be evacuated to Novosibirsk and Kazan. The Institute equipment and the Institute employees with their families were directed to the new site, where, at the earliest possible date, the laboratories were made to resume functioning. On December 29, 1941, S. A. Chaplygin reported to the People's Commissar, A. I. Shachuryn, about the operation of the Novosibirsk branch of the Institute, "There are 500 employees in the Novosibirsk branch of TsAGI including from 60 to 70 leading scientists and skilled engineers; TsAGI have made contacts with eastern aircraft factories to improve production and experimental war-planes; modern aerodynamic and solidstate laboratories are being built for the support of aircraft factories. While organizing the centre we had already been thinking of a problem which will arise soon, i.e., of the forthcoming return of some departments to Moscow in the near future." Re-evacuation was initiated one year after this report was made.

During 1941-1945, an exhibition of domestic, enemy's, and ally's airplanes was held in the TsAGI exhibition hall. About 100,000 pilots, engineers, and technicians worked 
there during the war. In 1945, the Order of Lenin was awarded to TsAGI for the great achievements in research work in the field of aviation.

A new period of TsAGI development began after the war. Jet aviation appeared in the shortest possible time (10-15 years) on the basis of fundamental research by TsAGI and other institutes. Theoretical and experimental research carried out under the direction of S. A. Khristyanovich made it possible to discover a wide range of high-speed aerodynamics laws. The invention of perforated wind tunnel operating parts permitted the conduction of experiments on transonic and supersonic gas jets. The construction of arrow-type wing theory by V. V. Struminsky was an essential contribution of TsAGI scientists to transonic and supersonic aviation.

New types of helicopters were being developed. The helicopter experimental design bureau was founded in 1947. M. L. Mil, the head of the TsAGI helicopter and spin laboratory, became the design manager of the bureau.

Completely new aircraft, with the new concept of interaction between the Institute and experimental design bureaus, have appeared. According to this interaction concept, TsAGI would give recommendations concerning aerodynamic structure and principal parameters on new airplanes. Furthermore, the bureau's and TsAGI's joint study of these parameters would become the basis of the project. After that, TsAGI would act as an expert body, approving the first flight of an airplane or launch of a rocket. Such cooperative work led to the fact that TsAGI managers were thoroughly acquainted with the design managers of all bureaus.

When nuclear weapons were invented, the aircraft industry had to produce aircraft that would be able to deliver them safely over long distances. This problem was solved. Strategic transonic long-distance aircraft Tu16, Tu95, M4, Tu22, and M50 were constructed in cooperation with Tupolev OKB and Miasyschev OKB, while the strategic ramjet engine cruise missile was constructed in cooperation with Lavochkin OKB. The missile had a range of action of about $8000 \mathrm{~km}$ and a cruising speed of up to Mach 3.2 (three times faster than the speed sound).

In 1957, the world was shocked by USSR achievements, which were the intercontinental missile and the first artificial satellite (Sputnik). TsAGI was involved in the research into the dynamic and aerodynamic characteristics of all artificial satellites and spacecraft, and was also involved in designing the $\mathrm{R} 7$ carrier rocket invented by S. P. Korolev. Space and rocket technology developed, and a new laboratory dedicated to fundamental research into hypersonic aerodynamics was established at TsAGI. A. A. Dorodnitsyn became the head of the laboratory.

In the 1960s, TsAGI scientists successfully solved the problem of developing an aerodynamic multiple-mode airplane structure involving a variable-geometry wing. The results of this development found an application in fighter aircraft MiG23 and MiG27, missile platforms Tu22M and Tu160, and attack aircraft Su24.

The vertical take off and landing aircraft Yak36 and Yak38, and high-speed aircraft MiG25 were constructed. Fundamental research into rotary aerodynamics allowed the 
creation of new-generation fighter aircraft MiG29 and Su27, which surpassed the best models of foreign fighter aircraft in aircraft performance characteristics.

Another important line of TsAGI investigation was civil aviation. The world's first jet airliner Tu104, high-speed airliners Tu154 and Il86 (Mach 0.8-0.85), long-haul airliners I196, Tu204, and An124, transport aircraft I176, and supersonic airliner Tu144 were created. In 1971, the Order of the October Revolution was awarded to TsAGI for great achievements in aircraft construction.

Much of TsAGI research was dedicated to the behavior of in-orbit satellites during ascent and reentry at Mach 20-30. The most complex problems appeared during the development of the booster rocket for the space shuttles Buran and Energia. TsAGI technologies helped with obtaining the necessary aerodynamic characteristics of the spacecraft based on real hypersonic flight, helped with improving spacecraft solidity and thermal insulation, and helped with understanding the acoustic load. Every significant step of the Buran and Energiya development was under TsAGI's control. The Buran pilotless flight and landing were extremely exact and accurate.

The personal contributions to aviation and space technologies in the 1960s and later made by V. M. Myiasyschev and G. P. Svishchev, the TsAGI heads in 1960-1967 and 1967-1987, respectively, is to be noted.

During the last decades, TsAGI scientists took an active part in creating new types of military and civil aircraft. Several TsAGI inventions, such as new generations of highbypass ratio engines, wings of high aspect ratio (derived from investigation of supercritical airfoil aerodynamics), and others, became the basis of military transport aircraft An124, medium-range airliner Tu204, long-haul airliner I196, and short-to-medium-range airliner Tu334. These airliners did not yield to their foreign analogues produced by Boeing and Airbus, the industry leaders. Unfortunately, Tu204, I196, and Tu334 were not as popular and mass-produced as their foreign analogues due to political and economic reasons.

To this date, the Institute includes the following four principal departments:

1. Department of aerodynamics, flight dynamics, and of future trends of aircraft development

2. Department of solidity, aeroelasaticity, and lifetime of aircraft

3. Department of engineering and improvement of experimental gear

4. Department of acoustics, hydrodynamics, and industrial aerodynamics

At present, technical re-equipment takes place at TsAGI. Wind tunnels, test benches, compressor systems, and power services are under reconstruction and modernization.

More than 3500 employees work for the Institute. Full Members and Corresponding Members of the Russian Academy of Sciences, more than 500 Doctors of Science and 
Candidates of Science, and hundreds of talented engineers are among them. All these people contribute to the scientific potential of TsAGI.

Conferences are constantly convened and aviation competitions are held within the departments of TsAGI. Each year, a jury presided over by the head of the Institute awards the Zhukovsky Prize and TsAGI Prize to domestic scientists.

Moscow Institute for Physics and Technology (MFTI) graduates, Moscow Aviation Institute (MAI) graduates, and Bauman Moscow State Technical University graduates form the majority of TsAGI employees. Two faculties are of prime importance, namely, the MFTI aeromechanics and aircraft faculty and the MAI "Strela" (Arrow) faculty. Both of them are situated in the town of Zhukovsky, and both of them train specialists for TsAGI and other aviation research institutes. However, scientific positions in the field of aviation are not so attractive due to their low salary. It will be a challenge for the Institute to recruit interns.

These days, the Institute's mission is to solve a very important problem, i.e., to reconstruct the Russian national aircraft industry. To solve such a problem, new aircraft concepts are being developed, and a new basis of aircraft and the space industry is being created. The RRJ and MC21 airliners being designed, it is to be noted. Research into new types of warplanes, helicopters involving jet engines, rockets, and both supersonic and hypersonic aircraft are being conducted. New composite materials are being introduced into aircraft construction, and new electric drives for lift devices are being introduced, replacing the old (hydraulic) ones. New control algorithms that will automate the whole process of flight from take off to landing are being created. New aircraft control methods involving modern miniaturized sensors, actuators, miniaturized flaps, etc. are being developed by TsAGI. Fundamental researches are being carried out that are dedicated to decreasing drag by laminarization of the airflow, by decreasing turbulent friction, by avoiding boundary layer separation, etc.

TsAGI specialists are investigating the concepts of new spacecraft that would be able to go into circumterrestrial orbit and fly to other planets. Numerous different structures of such spacecraft are being studied by the Institute in cooperation with various design bureaus. These structures include capsular structure, load-carrying skeleton structures, and winged spacecraft with fixed or transforming planes. The fundamental researches into new mathematic models, programs, and methods of solving the most complex, multivariate, and nonlinear aerogas dynamics problems are being conducted by TsAGI and the Russian Academy of Sciences involving supercomputers and aiming to create new types of aircraft and spacecraft.

TsAGI has preserved its scientific potential. The Institute is able to design new types of equipment, develop aviation and space science, and train specialists. We expect that the government program concerning aviation development will renew the Russian aviation science and aircraft industry. 